\title{
Analysis on the Reform of Design Color Teaching Method
}

\author{
Zhenglei Dong \\ Huanghe Science and Technology College \\ Zhengzhou, China
}

\begin{abstract}
Design color is an important content of modern art design education and an important means of design performance. Design color expresses and presents space by means of color induction, generalization and refining based on the study of natural color, according to the characteristics and requirements of the art design major, which is a professional course that emphasizes the use of color, and explores human's rational thinking and creative thinking with the combination and change principle of color, an important part of design teaching. Modern design color teaching should gradually build a set of complete design color system for expression and use of subjective color so as to surpass imitation to reach initiative awareness and creation, and lay a good foundation for future design.
\end{abstract}

Keywords-design color; teaching method; reform

\section{INTRODUCTION}

Design color teaching is the basic content of basic courses of design, and the perfection of design color teaching system plays an important role in the color and even the entire design. "Modern Chinese Dictionary" defines "design" as follow: "before formally doing a work, develop methods and drawings, etc. in advance according to certain objectives and requirements". In design activities, as another design element in addition to form, color is an irreplaceable way of information transmission and one of the most attractive design factors. At present, the design color teaching has gradually formed chromatics different from the painting major, which has a clear design awareness, art the purpose of color teaching in design major is to enable students to master color principles and color matching methods, to lay a professional basis for design. With the progress of the times, the teaching concept is continuously updating, and only continuous study on design color teaching can promote the development of design color teaching. This paper discusses the innovation of design color teaching in art design, and talks about my personal teaching experience from the following three aspects.

\section{Cultivate STUdents' COLOR Literacy AND INNOVATIVE CONSCIOUSNESS OF DESIGN COLOR}

In design color teaching, to cultivate students' color literacy and innovative consciousness of design color, it should rid students of the traditional painting mode, emphasize the design initiative, color summary method and plane consciousness, and create students' color literacy and innovation awareness of design color. China's art and design education started late, and the teaching system and mode, the curriculum setting are effected by the synthesis combining former Soviet Union's art education system and the French impressionism's light color theory, although in a period of time, this system does play a very beneficial role, today it's urgent to improve and strengthen the new teaching model and content. The main problem in the current design color teaching is that the teachers simply convey the teaching content of the design color curriculum to students but do not mobilize the passion and learning initiative of the students. Secondly, too much emphasis is placed on traditional painting's color sketching methods, or students are guided to fully use subjective color, which results in disconnection to the designed color requirement, in fact, only when the color is created based on design will it be more valuable.

The composition of design color teaching should have the content of color sketching and color composition, and the color sketching can make students understand various changes of the object itself in the specific environment and the color laws. In teaching, the color of subjective awareness can be collated based on natural color to cultivate students' modeling consciousness of subjective color in sketching, for example, the study of color modeling should firstly be established based on basic ideas such as the observation and analysis method of natural color, the understanding of the law and the practice of color sketching, focus on guiding students to collate and develop the content they see, to turn the visual experience of natural color into aesthetic condition, so that students can express with specific way of thinking of color, and turn the image into a visual color effect. The painting color is emotional, objective, spatial and real, while the design color is rational, subjective and plane. For example, the plane consciousness of color can not only make beginners of design color control the basic method of color generality from simple to complex in the process of design color and still-life painting of students, more importantly, it allow students to experience the skills and energy essence of modern design color's charm performance, so the color concept of the opposite side should be added in painting color and design color training. Such sketching process in the form of color sketching is different from the traditional reproduction, but requires students to observe with the eyes and think with the mind, to sketch for the purpose of re-creation. American educator Luofeier once pointed out: "In art education, he is only the tool used to achieve the purpose, and he himself is not the purpose. The 
purpose of art education is to make people more creative through creative procedure.

Design color is different from painting color, which needs to strengthen student's color ideas and creative thinking ability, and give full play to students' subjective initiative at the same time, through color training, blend in design consciousness, break narrow and limited color concept, so as to enable students to have strong color literacy and innovative awareness of design color. The color teaching of art design color shall improve students' comprehensive color literacy, train students' ability of color expression, imagination, creativity and a wide color awareness and aesthetic to meet the development needs of the design disciplines of the times. Helping students gradually build two sets of complete subjective color expression and use of the design color system and giving students creative design thinking space will significantly improve students' color design literacy and color aesthetic ability.

\section{Cultivate Students' APPlicAtion Ability OF COLOR DESIGN}

The study of color design must be synchronized with the overall structure of the design, so as to closely link the basic skills to expertise, organically combine the design and color design, and more freely expand the required learning content based on the previous study of color, and make color study one of the most active courses in accepting all kinds of information. Therefore, in the beginning of teaching, design color teaching shall be more linked to the actual design consciously, and more attention shall be paid to in guiding students' consciousness of independent design based on ensuring the basic color theory teaching, to make it have a certain creativity and purpose.

Design color is a basic course of art design major, which plays an important role in modern art design, such as advertising design, packaging design, industrial design, environment design and fashion design. Various design categories and colors are in various relationships, in various design categories, the coordination and correct use of color is a guarantee for the product to successfully go to the market. To cultivate students' application ability of color design is to require them to directly enter the design color use, and implement color design by combining with the major. The previous color training is not involved in the content of design major, and this training mode combined with major can improve the design teaching, for the actual color design makes students fully enter the design role in the first time. The design colors mainly expresses the plane, simple and orderly form, and the images appearing in art design, whether it is twodimensional or three-dimensional image, are in a plane state in composition, which makes the image have aesthetic appeal and expressiveness, and forms a picture with a sense of order, rhythm and cadence effect. For example, in advertising design performing plane, purity and order, if the color does not express what it wants to express, it will lose the meaning of design. Emphasize the premise of practicability, pay attention to public acceptance, require the color effect to be explicit, clear and simple, conform to the requirements of the design theme, express a higher realm of color to meet the design. After such training, students can directly design, and courses are also correlated to each other, at the same time, according to the practical needs of the design application field, factors related to the overall design such as the color principle, marketing, business strategy, product appearance and color will also be considered, understanding of color will be subject to a series of factors such as the material, processing technology, technology condition, economic cost and popular information of color, which only consider the color design which constitute itself in the application design. Such practical application ability requires students not only to have rich imagination and ability of color control, but also have a certain professional capacity and higher personal aesthetic artistic accomplishment at the same time.

Therefore, as a future designer, one must firstly understand the past, understand today, and look forward to tomorrow, and then rely on the actual design application to obtain the most contemporary color design work.

\section{IMPROVEMENT OF DESIGNING COLOR TEACHING METHOD}

There are many design color teaching methods, but the most effective ones are as follows:

\section{A. Color Induction Performance}

Color inductive performance is to understand how to transform the three-dimensional objects to two-dimensional plane and to understand the process of transformation from realistic performance form to design performance form by mastering the analysis, generalization and refinement of natural color. Color inductive training is an effective measure to communicate realism with subjective color painting. Inductive color sketching is to handle in the color which is not affected by the light color shadow II, and to consciously pursue the effect of plane picture, ignore the small color, and present in the overall effect, so the inductive color sketching can cultivate students' use of subjective color. When the color is induced to a certain extent, it can also exercise with the restrictive performance method of color, and produce different color patterns with only a few different collocation forms of color. This performance form can train students' way of feeling and thinking, which is an enhancement of the ability to highly summarize and induce the color of images, also a common way to train students' subjective color performance, and an important means to test subjective color imagination.

\section{B. The color's Decorative Performance}

The decorative performance of color is another kind of means to train students' design thinking ability and design expression, whose core content is subjectivity, expressing the picture with exaggerated color, using performance techniques such as induction and exaggeration symbol, paying attention to color's own rhythm and decorative effect. Decorative color performance is a common method of impressionist and modernist painters, for example, Gauguin's series of works, Tahitian and Van Gogh's series of works, Sunflower, both used color's decorative performance techniques. The practice of color's decorative performance should start from induction and sketching, step by step, emphasize its decorativeness on 
the basis of color induction as much as possible, embodying the depicting techniques of color effect, such as color interspersing, delineating and outlining, gradual change and interval color, which can strengthen the richness and decorativeness of the picture color, make which show a harmonious color effect.

\section{Color Abstract Performance}

Color abstraction performance requires to get rid of the dependence of vision on the direct recognition of image, to cultivate students' ability of design thinking, which is an important part of design expression, taking the image and color from nature, and gradually making them out of nature, so that there is abstract function of hint, symbol, idea conveying between the color and form. Color abstraction performance can be achieved through some proposition design, for example, the design color theme of China can be set, we know that China has vast territory and abundant resources, and the color perception and application are very different in different areas. Due to their own factors such as experiences, cultural background and personality, students will have different color performance on the same theme. In abstract practice, students can find a starting point to start development, and can design color according to their own ideas and emotional expression, transform the specific image to abstract object, take abstract elements such as point, line and plane as the performed image to form their own work, and consider the aesthetic commonality in the pursuit of creative personality. Therefore, after careful analysis, it is necessary correctly express the understanding of specific image and specific feelings with the appropriate color and color expression mode. Different performance of the same theme has different rhythm and tone, and individuation can give a different sense of beauty, generality brings the same sense of identity. If there is a proposition, there is color creativity, which is a higher level of rational thinking, the role and expression form of emotional thinking, through the training in this course, students will change the dependence on image's color, change from passive to active, more actively mobilize their potential color perception and creativity, and feel they can design color completely according to their own ideas and the need of emotional expression.

\section{CONCLUSION}

Through the understanding of design color characteristics, students rise to practical practice from theoretical learning, rise to rational knowledge from perceptual knowledge, from scientific observation of the color of painting and sketching, to rationally and subjectively induce design color, to creatively use color in all types of design. The process starts from the cultivation of students' understanding of color, and ability to vividly expressing design color level, master different design color methods, and play a role in different fields of artistic design in the future, la a solid foundation for correct use of color and design color in art design major future.

\section{REFERENCES}

[1] Feng Jianqin. Color [M]. Jiangsu Fine Arts Publishing House, 1994.
[2] Ma Ye. Color Foundation [M]. Liaoning Fine Arts Publishing House, 2006.

[3] Xi Yueliang. Color and design color [M]. Tsinghua University Press, 2006.

[4] Li Liting. Color composition [M]. Hubei Fine Arts Publishing House, 2001. 